\title{
Impact of sertraline on serum concentration of CRP in hemodialysis patients with depression
}

\author{
Narges Sadat Zahed, Marjan Sharifi*, Mahdi Karimi, Hajar Nikbakht \\ Loghman Hakim Clinical Research Development Center, Shahid Beheshti University of Medical Sciences, Tehran, Iran
}

\section{ART I C L E IN F O}

Article Type:

Original

\section{Article History:}

Received: 9 June 2016

Accepted: 5 August 2016

Published online: 26 August 2016

Keywords:

Depression

Hemodialysis

Inflammation

CRP

Sertraline

BDI-II score

\begin{abstract}
A B S T R A C T
Introduction: Depression is the most prevalent psychological problem among hemodialysis (HD) patients. Inflammatory factors have been reported to play an important role in the pathogenesis of depression. The association between depression and inflammatory factors was established in chronic kidney disease (CKD) patients. Sertraline, a selective serotonin reuptake inhibitor (SSRI) antidepressant, decreases serum levels of inflammatory factors in patients with depression.

Objectives: This study was designed to assess the effect of sertraline on serum concentration of C-reactive protein (CRP), hemoglobin and albumin of depressed hemodialysis (HD) patients.

Patients and Methods: During a clinical trail, 35 depressed HD patients, and CRP $>5$ were allocated to receive sertraline for 12 weeks. Patients' depression was assessed using Beck depression inventory second edition (BDI-II) biochemical parameters (hemoglobin, serum albumin, etc) and CRP levels were measured at baseline and at weeks 4, 8 and 12 of the study. BDI-II score was evaluated before and after 12 weeks treatment with sertraline.

Results: Sertraline significantly improved depression symptoms in HD patients. At the end of the study, BDI-II scores significantly changed from baseline $(P=0.001)$ and serum levels of CRP significantly decreased at week 12 of initiation of the study $(P=0.001)$. However, the concentration of hemoglobin and serum albumin concentration and weight was not changed significantly $(P=0.995$ and $P=0.328$, respectively).

Conclusion: Sertraline significantly decreases CRP levels and can be a promising strategy to reduce the systemic inflammation and to treat depression in HD patients.
\end{abstract}

Implication for health policy/practice/research/medical education:

Depression is the most prevalent psychological problem among hemodialysis (HD) patients. Inflammatory factors have been reported to play an important role in the pathogenesis of depression. Patients' depression was assessed using Beck depression inventory second edition (BDI-II) biochemical parameters and C-reactive protein (CRP) levels were measured at baseline and at weeks 4,8 and 12 of the study. This study was designed to assess the effect of sertraline on serum concentrations of CRP, hemoglobin and albumin of depressed HD patients. Sertraline significantly decreases CRP levels and can be a promising strategy to reduce the systemic inflammation and to treat depression in HD patients.

Please cite this paper as: Zahed NS, Sharifi M, Karimi M, Nikbakht H. Impact of sertraline on serum concentration of CRP in hemodialysis patients with depression. J Renal Inj Prev. 2017;6(1):65-69. DOI: 10.15171/jrip.2017.12.

\section{Introduction}

Chronic kidney disease (CKD) is a range of different pathophysiologic processes lead to abnormal renal function and decline in glomerular filtration rate. CKD is an inflammatory condition which is associated with an increasing in acute phase reactants, such as circulating inflammatory cytokines and C-reactive protein (CRP) and also decreasing in negative acute phase reactants, such as serum albumin and fetuin (1).
CRP is a sensitive marker of inflammation and tissue damage. CRP production is under the IL6 control with a fast rise by pathological stimuli and after pathological agents subsidence, CRP levels quickly drop (2). Depression is a common problem in patients with end-stage renal disease (ESRD) undergoing hemodialysis (HD). Depression prevalence in the general population is $7 \%-10 \%$ while in studies among CKD patients is $20 \%(3,4)$.

Chronic inflammation is common in patients with ESRD 
undergoing chronic HD and associated with atherosclerosis, cardiovascular diseases, malnutrition and increased mortality rate (4). It is established that inflammatory factors such as CRP and IL6 rise in ESRD patients (5). Chronic inflammation plays an important role in the pathophysiology of depression (6). Some previous studies detected increasing inflammatory markers such as CRP, interleukins, ferritin and erythrocyte sedimentation rate (ESR) in CKD patients, leading to deterioration of depression and subsequent malnutrition, atherosclerosis, cardiovascular morbidity and mortality in $\operatorname{ESRD}$ patients $(7,8)$. Patients with ESRD and depression, have higher levels of CRP and serum ferritin levels. Whereas hemoglobin, hematocrit and albumin were lower among ESRD patients without major depression (9). It seems that reduction in inflammatory factors in ESRD patients could reduce depression and subsequently decreases cardiovascular events and mortality rate (10).

It is suggested that antidepressant drugs which have also anti-inflammatory effects, may lead to decline the levels of inflammatory markers $(11,12)$.

According to studies, the best antidepressant medicine for the treatment of depression

in patients with ESRD is sertraline. In addition to treating depression, sertraline is capable to reduce pro-inflammatory cytokines and CRP $(13,14)$.

In most studies BDI is used to screen patients in which 21 items is used to measure depressive symptoms and total score is ranged from 0 to 63 . In the general population depression inventory second edition (BDI) scores $>10$ need treatment while in CKD patients BDI score $>14$ is considered for medical therapy (15).

Sertraline as the first line treatment is well tolerable in patients with ESRD and does not need dose adjustment $(16,17)$. In the general population treatment with sertraline reduced the pro-inflammatory cytokines like IL2, IL4 and increased the anti-inflammatory cytokines (18).

\section{Objectives}

In this study, we aimed to assess the impact of sertraline, as a selective serotonin reuptake inhibitor (SSRI) antidepressant, on inflammatory markers among HD patients with major depression.

\section{Patients and Methods}

In this investigation, 51 depressed patients fulfilled the inclusion criteria. However, according to drug side effects, death and hospital admission, 43 patients were investigated finally.

The inclusion criteria were as follows: CRP> $5 \mathrm{mg} / \mathrm{dL}$, age older than 18 years, undergoing dialysis for at least 3 months, and BDI score $>14$.

Patients were excluded if they had active infections, malignancy, autoimmune disease, severe mental illness or cognitive disorders, sertraline hypersensitivity, treatment with NSAIDs, antibiotics or steroids one month before the study.

All of our participants needing medical treatment had
BDI score $>14$ because ethical committee did not permit to have a placebo group in the present study.

Patients were under treatment for 12 weeks. Sertraline was administered $50 \mathrm{mg} /$ day as an initial dose. Each two weeks, participants were visited and the drug dose could increase if necessary until reaching maximum dose of 200 $\mathrm{mg} /$ day.

At the beginning of the study, CRP, complete blood count (CBC), albumin, hemoglobin and patients' weight were evaluated. After 12 weeks of treatment, patients' depression was evaluated by Beak II.

\section{Ethical issues}

The research followed the tenets of the Declaration of Helsinki; informed consent was obtained; and the research was approved by the ethical committee of Shahid Beheshti University of Medical Sciences.

\section{Statistical analysis}

Data was analyzed using SPSS version 18 (SPSS Inc., Chicago, IL, USA). Results are shown as mean \pm SD or median for normally or not-normally distributed continuous variable and number or percentages in the case of nominal variables. To evaluate before and after changes paired $t$ test was used. $P<0.05$ was considered as significant.

\section{Results}

Baseline parameters like demographic characteristics dialysis duration and etiology of ESRD are shown in Table 1. The mean of BDI-II score at week 0 was $21.4 \pm 6.98$ and after 12 weeks of treatment decreased to $13.31 \pm 5.59$ which was statistically significant $(P=0.005)$.

The effect of sertraline on CRP after 12 weeks was statistically significant (Figure 1; $P=0.001$ ) whereas, albumin and hemoglobin did not change significantly (Table 2; Figures 2 and 3).

\section{Discussion}

This study has evaluated the effect of sertraline on inflam-

Table 1. Patients' characteristics

\begin{tabular}{ll}
\hline Parameter & Value \\
\hline Age (years) & \\
Median (range) & $60.8 \pm 13.8$ \\
Median (range) & $62(27-79)$ \\
Sex & \\
Female & $21(60 \%)$ \\
Male & $14(40 \%)$ \\
Dialysis duration & \\
Mean \pm SD & $5.76 \pm 3.4$ \\
Median (range) & $4(1-18)$ \\
Etiology of ESRD & \\
HTN & $9(25.8 \%)$ \\
Diabetes & $18(51.4 \%)$ \\
Other causes & $8(22.8 \%)$ \\
\hline
\end{tabular}


Table 2. Parameters mean changes

\begin{tabular}{|c|c|c|c|c|c|}
\hline Parameters & Week 0 & Week4 & Week 8 & Week 12 & $P$ value \\
\hline weight (kg) & $62.7 \pm 13$ & $62.3 \pm 12$ & $62.5 \pm 12.9$ & $62.4 \pm 12.9$ & 0.569 \\
\hline CRP (mg/dL) & $33.5 \pm 24.2$ & $21.8 \pm 13.3$ & $16.5 \pm 12.6$ & $15.4 \pm 12.6$ & 0.000 \\
\hline Albumin (g/dL) & $3.09 \pm 0.86$ & $4.07 \pm 0.57$ & $3.94 \pm 5.7$ & $4.17 \pm 0.57$ & 0.328 \\
\hline $\mathrm{WBC}\left(10^{3} / \mathrm{mm}^{3}\right)$ & $7.47 \pm 4.8$ & $7.33 \pm 3.1$ & $7.6 \pm 3.04$ & $7.26 \pm 2.7$ & 0.982 \\
\hline $\mathrm{Hb}(\mathrm{g} / \mathrm{dL})$ & $11.3 \pm 1.7$ & $11.7 \pm 1.4$ & $11.4 \pm 1.5$ & $11.3 \pm 1.7$ & 0.995 \\
\hline $\operatorname{PLT}\left(10^{3} / \mathrm{mm}^{3}\right)$ & $187 \pm 77$ & $183 \pm 69$ & $201 \pm 78$ & $202 \pm 87$ & 0.713 \\
\hline $\mathrm{Na}(\mathrm{mEq} / \mathrm{L})$ & $139 \pm 4$ & $138 \pm 3$ & $137 \pm 6$ & $137 \pm 3$ & 0.133 \\
\hline $\mathrm{K}(\mathrm{mEq} / \mathrm{L})$ & $5.5 \pm 0.8$ & $5.4 \pm 0.8$ & $5.7 \pm 1.1$ & $5.8 \pm 1.1$ & 0.462 \\
\hline
\end{tabular}

Abbreviations: CRP, C-reactive protein; WBC, white blood cell; $\mathrm{Hb}$, hemoglobin; PLT, platelet; Na, sodium; $\mathrm{K}$, potassium

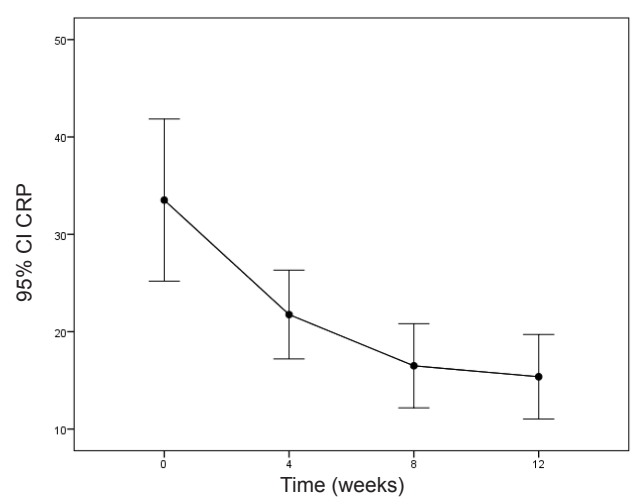

Figure 1. Effect of sertralin on CRP after 12 weeks of treatment.

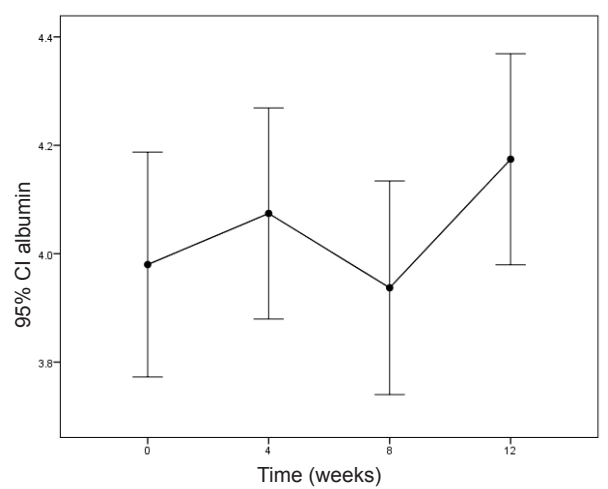

Figure 2. Effect of sertralin on albumin after 12 weeks of treatment.

mation markers in HD patients.

According to results, sertraline had anti-inflammatory effect and decreased the CRP as an inflammatory marker. The study conducted by Dashti et al on $300 \mathrm{HD}$ patients showed high levels of CRP, and low albumin levels were highly prevalent among ESRD patients and resulted in morbidity and mortality (6).

In the current study, we found CRP $>5 \mathrm{mg} / \mathrm{dL}$ in $57 \%$ of participants, which was as same as previous studies, while hypoalbuminemia was not found in our study. Kalender et al showed accompany of high levels of CRP and decrease in albumin and hemoglobin in HD patients with depression (16).

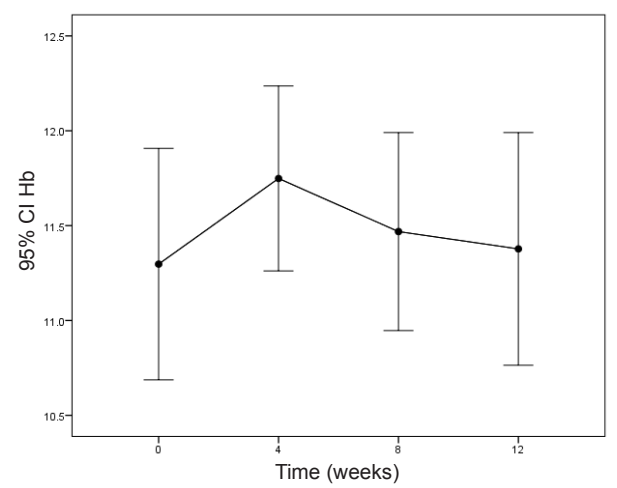

Figure 3. Effect of sertralin on $\mathrm{Hb}$ after 12 weeks of treatment.

In our study, we found depression among 51 patients with high CRP levels. Although previous studies $(6,19)$ evaluated the impact of sertraline on CRP levels in comparison with the placebo group, in our study, according to BDI score $>14$, it was not permitted by the ethics committee to consider the placebo group without treatment.

Additionally, Dogan et al (15) found a significant correlation of depression score and levels of CRP whereas in our study, we had patients with very high CRP levels whose depression score was low.

In one study, CRP levels was measured before and after treatment, while we concluded that antidepressant drugs, not only treated depression, but also reduced inflammatory markers (20).

Likewise, in CAST study sertraline was administered as an antidepressant drug in CKD patients which could improve nutrition, quality of life and depression signs (21). The present clinical trial evaluated the impact of the sertraline effect ( $50 \mathrm{mg} /$ day).

Some adverse events like headache and dizziness were observed in the fewest number of participants, which resolved by decreasing the sertraline dose and only two patients were refused to complete the study.

We also found the significant decrease in CRP levels after 4 weeks of treatment. In line with our results, Pizz et al showed decline in CRP levels after treatment with sertraline among patients with cardiovascular disease too (19). However, in a study on patients with coronary heart dis- 
ease and comorbid major depression, the increase in CRP levels by sertraline therapy was found (20).

Tuglu et al (21) and O'Brien et al (17) suggested significant decrease in CRP plasma levels by SSRI therapy in depressive population.

In this study, we did not find significant changes in albumin levels after 4, 8 and 12 weeks of treatment in HD patients, whereas Koo et al showed treatment with paroxetine leading to increase in albumin levels (22).

Albumin is a protein which is related to diet and oral intake. Inflammatory markers such as cytokines result in activating protein catabolism and malnutrition. It seems that, treatment with antidepressant drugs improves oral intake and also declines in protein catabolism. In a study by Lee et al depression led to insufficient oral intake in HD patients and after treatment of depressive disease weight gain was detected among studied population (23). Despite the improved appetite in our study, we did not find the increase in serum albumin value and an improvement of weight gain. This different result may be due to differences of the patients' diet.

Significant changes in hemoglobin levels was not detected. Our findings was in line with Kalantar-Zadeh et al (24). We could not control and set the erythropoietin dose weekly, thus, hemoglobin levels did not show significant changes in this study.

\section{Conclusion}

Sertraline is an SSRI which does not need dose adjustment in ESRD or HD patients and also has few tolerable adverse events. Administration of sertraline may lead to a decrease in inflammatory markers and also improvement of depressive signs leads to better quality of life, reduced morbidity and finally mortality among HD patients. Therefore, more studies are needed to determine the appropriate doses.

\section{Limitations of the study}

The limitations of our study were the small sample size and short duration of the investigation.

\section{Acknowledgments}

This study was presented as a poster presentation at International Congress of Nephrology \& Urology on June 12, 2015 in Tehran.

\section{Authors' contribution}

NSZ has designed the study and observed accuracy and validity of study protocols. MS collected data and followed the studies objects. HN wrote the article and edited the manuscript.

\section{Conflicts of interest}

The authors declare no conflict of interest.

Ethical considerations

Ethical issues (including plagiarism, data fabrication, double publication) have been completely observed by the authors.

\section{Funding/Support}

This article is extracted from internal medicine residential thesis of Marjan Sharifi (Thesis \#296).

\section{References}

1. Kathleen DL, Glenn MC. Dialysis in the treatment of renal failure, Longo, Fauci, Kasper. In: Harrisons Principles of Internal Medicine (vol 2). 18th ed. New York: McGrawHill; 2011.

2. Pepys MB, Hirschfield GM. C-reactive protein: a critical update. J Clin Invest. 2003;111:1805-12. doi: 10.1172/ JCI18921.

3. Hedayati SS, Minhajuddin AT, Toto RD, Morris DW, Rush AJ. Validation of depression screening scales in patients with CKD. Am J Kidney Dis. 2009;54:433-9. doi: 10.1053/j. ajkd.2009.03.016.

4. Hedayati S, Yalamanchili V, Fredric O. Finkelstein. A Practical approach with chronic kidney disease and endstage renal disease 2012 international society of Nephrology. Kidney Int. 2012;81:247-55. doi: 10.1038/ki.2011.358.

5. Craven JL, Rodin GM, Littlefield C. The Beck Depression Inventory as a screening device for major depression in renal dialysis patients. Int J Psychiatry Med. 1988;18:36574. doi: 10.2190/M1TX-V1EJ-E43L-RKLF.

6. Dashti1 N, Einollahi1N, Nabatchian1 F, Sarabi MM, Zarebavanil M. Significance of albumin and C-reactive protein variations in 300 end stage renal disease patients in Tehran University of Medical Sciences hospitals during year 2010. Acta Medica Iranica. 2012;50:197-202

7. Eller T, Vasar V, Shlik J, Maron E. Pro-inflammatory cytokines and treatment response to escitalopram in major depressive disorder. Prog Neuropsychopharmacol Biol Psychiatry. 2008;32:445-50.

8. Qureshi AR, Alvestrand A, Divino-Filho JC. Inflammation, malnutrition, and cardiac disease as predictors of mortality in hemodialysis patients. J Am Soc Nephrol. 2002;13 Suppl 1:S28-36.

9. Ko GJ, Kim MG, Yu YM, Jo SK, Cho WY, Kim HK. Association between depression symptoms with inflammation and cardiovascular risk factors in patients undergoing peritoneal dialysis. Nephron Clin Pract. 2010;116:c29-c35 doi: 10.1159/000314548.

10. Lanquillon S, Krieg JC, bening-Abu-Shach U, Vedder $\mathrm{H}$. Cytokineproduction and treatment response in major depressive disorder. Neuropsychopharmacology. 2000;22:370-9. doi: 10.1016/S0893-133X(99)00134-7.

11. Sutcigil L, Oktenli C, Musabak U, Bozkurt A, Cansever A, Uzun $\mathrm{O}$, et al. Pro- and anti-inflammatory cytokine balance in major depression: Effect of sertraline therapy. Clin Dev Immunol. 2007;2007:76396. doi: 10.1155/2007/76396.

12. KuberaM, Lin AH, Kenis G, Bosmans E, van Bockstaele D, Maes M. Anti effects of antidepressants through suppression of the interferon-/interleukin-10 production ratio. J Clin Psychopharmacol. 2001;21:199-206

13. Lee SK, Lee HS, Lee TB, Kim DH, Koo JR, Kim YK, et al. The effects of Antidepressant treatment on serum cytokines and nutritional status in hemodialysis patients.J Korean Med Sci. 2004;19:384-9. doi: 10.3346/jkms.2004.19.3.384. 14. Riezebos RK, Nauta KJ, Honig A, Dekker FW, Siegert CE. 
The association of depressive symptoms with survival in a Dutch cohort of patients with end-stage renal disease. Nephrol Dial Transplant. 2010;25:231-6. doi: 10.1093/ndt/ gfp383.

15. Dogan E, Erkoc R, Eryonucu B, Sayarlioglu H, Agargun MY. Relation between depression, some laboratory parameters, and quality o life in hemodialysis patients. Ren Fail. 2005;27:695-9. doi: 10.1080/08860220500242728.

16. Kalender B, Ozdemir AC, Koroglu G. Association of depression with markers of nutrition and inflammation in chronic kidney disease and end-stage renal disease. Nephron Clin Pract. 2006;102:c115-21. doi:10.1159/000089669.

17. O'Brien SM, Scott LV, Dinan TG. Antidepressant therapy and C-reactive protein levels Br J Psychiatry. 2006;188:44952. doi: 10.1192/bjp.bp.105.011015.

18. Jain N, Trivedi MH, Rush AJ. Rationale and Design of the Chronic Kidney Disease Antidepressant Sertraline Trial (CAST). Contemporary Clinical Trials 2013;34:136-44. doi: 10.1016/j.cct.2012.10.004.

19. Pizzi C, Mancini S, Angeloni L, Fontana F, Manzoli L, Costa GM. Effects of selective serotonin reuptake inhibitor therapy on endothelial function and inflammatory markers in patients with coronary heart disease. Clin Pharmacol Ther. 2009;86:527-32. doi: 10.1038/clpt.2009.121.
20. Bot M, Carney RM, Freedland KE, Rubin EH, Rich MW, Steinmeyer BC, et al. Inflammation and treatment response to sertraline in patients with coronary heart disease and comorbid major depression. J Psychosom Res. 2011;71:137. doi: 10.1016/j.jpsychores.2010.11.006.

21. Tuglu C, Kara SH, Caliyurt O, Vardar E, Abay E. Increased serum tumor necrosis factor-alpha levels and treatment response in major depressive disorder. Psychopharmacology (Berl). 2003;170:429-33. doi: 10.1007/s00213-003-1566-z.

22. Koo JR, Yoon JY, Joo MH, Lee HS, Oh JE, Kim SG, et al. Treatment of depression and effect of antidepression treatment on nutritional status in chronic hemodialysis patients. Am J Med Sci. 2005;329(1):1-5. doi: 10.1097/00000441-200501000-00001.

23. Lee SK, Lee HS, Lee TB, Kim DH, Koo JR, Kim YK, et al. The effects of antidepressant treatment on serum cytokines and nutritional status in hemodialysis patients. J Korean Med Sci. 2004;19:384-9. doi: 10.3346/jkms.2004.19.3.384.

24. Kalantar-Zadeh K, McAllister CJ, Lehn RS, Lee GH, Nissenson AR, Kopple JD. Effect of malnutrition-inflammation complex syndrome on EPO hyporesponsiveness in maintenance hemodialysis patients. Am J Kidney Dis. 2003;42:761-73. doi:10.1016/S0272-6386(03)00915-6

Copyright (c) 2017 The Author(s); Published by Nickan Research Institute. This is an open-access article distributed under the terms of the Creative Commons Attribution License (http://creativecommons.org/licenses/by/4.0), which permits unrestricted use, distribution, and reproduction in any medium, provided the original work is properly cited. 